\title{
Utilização de recursos mediacionais para a identificação de estressores em pré-escolares
}

\author{
Célia Vectore \\ Luciana de Souza Zumstein
}

\begin{abstract}
Resumo
Compreender aspectos relacionados ao estresse infantil por meio do uso de recursos mediacionais foi o objetivo do presente estudo. Os dados foram oriundos de entrevistas com as mães de pré-escolares; da aplicação da escala sobre fontes estressoras na infância; da observação da rotina institucional; da elaboração de um recurso mediacional ( $k i t)$ e do conhecimento dos critérios mediacionais utilizados pela pesquisadora, de acordo com o Programa Mediational Intervention for Sensitizing Caregivers - MISC. Os resultados junto às mães foram incongruentes com os obtidos junto às crianças, já que aquelas apontaram um grande número de estressores e, das dezesseis crianças participantes, apenas uma apresentou sintomatologia indicativa de estresse. $O$ instrumento pode ser utilizado para conhecer o que as crianças sabem sobre o estresse e, simultaneamente, intervir, possibilitando a expressão da criança acerca dos estressores. Novos estudos deverão ser efetivados, buscando compreender a dissonância dos dados das mães com os obtidos pelas crianças.
\end{abstract}

Palavras-chave: Estresse, crianças, avaliação do estresse.

\section{Stress: the use of mediating resources in identifying stressors in pre-school children}

\begin{abstract}
This study aims to understand aspects related to children stress through the use of mediating resources. In order to achieve that goal, semistructured interviews with pre-school children's mothers were carried out, besides applying the stressors sources scale to the child. To perform the collection of data from the children, workshops were organized and a meditational tool present in "Mediated Intervention for Sensitizing Caregivers - MISC. The results obtained through the scale with the mothers indicated a high possibility, however, the data obtained from the children, some incongruity between the data was noted, since only one of the sixteen participant children showed some symptoms of stress. The designed tool as a form of finding out what the children knew about the stress, and to enable the child to express the several indicative form of stress. New studies will also have to be carried out to understand the dissonance between the mothers'data and the children's ones.
\end{abstract}

Keywords: Stress, children.

\section{Uso de recursos mediacionales para la identificación de estresores en pre-escolares}

\section{Resumen}

El objetivo del presente estudio fue comprender aspectos relacionados al estrés infantil, por medio del uso de recursos mediacionales. Los datos provinieron de entrevistas con las madres de pre-escolares; de la aplicación de la escala sobre fuentes estresoras en la infancia; de la observación de la rutina institucional; de la elaboración de un recurso mediacional (kit) y del conocimiento de los criterios mediacionales utilizados por la investigadora, de acuerdo con el Programa Mediational Intervention for Sensitizing Caregivers- MISC. Los resultados con las madres fueron incongruentes con los obtenidos con los niños, ya que ellas indicaron un gran número de estresores y, de los dieciséis niños participantes, apenas un presentó sintomatología indicativa de estrés. El instrumento puede ser utilizado para conocer lo que los niños saben sobre el estrés y, simultáneamente, intervenir, posibilitando la expresión del niño acerca de los estresores. Nuevos estudios deverán ser realizados para comprender la disonancia de los datos de las madres con los obtenidos con los niños.

Palabras-clave: estrés infantil; intervención mediacional; evaluación del estrés. 


\section{Introdução}

A infância, em especial o estágio de vida pré-escolar, exige uma ampla variedade de cuidados, que vão desde aspectos mais elementares, como saúde e educação, até preocupações com o desenvolvimento da subjetividade infantil, a qual se encontra intimamente atrelada ao modo como as crianças vivenciam e representam a realidade. Contudo, o que é ser criança na contemporaneidade? Quais as suas demandas? Como entender o desenvolvimento, num contexto em que as idiossincrasias da infância parecem ser, a cada instante, substituídas por exigências próximas às enfrentadas pelos adultos?

Responder às questões elencadas não é tarefa fácil mediante a necessidade de se considerar a multiplicidade de fatores que envolvem a construção de seres humanos em uma sociedade complexa e acelerada. Há a competitividade exacerbada e a pressão contínua por melhores performances e a necessidade de adaptações contínuas aos novos arranjos sociais, às novas formas de constituição de famílias e aos novos modos de interação, em que o contato cara a cara é substituído pelo virtual. Enfim, há grandes demandas para a rápida adaptação do organismo, as quais podem constituir-se em novas formas de adoecimento físico e psíquico a gravitarem no universo da criança pequena.

Vale constatar que a própria concepção do que é ser criança sofreu uma série de modificações ao longo dos tempos, indo do descaso no passado até o amplo reconhecimento acerca de sua importância no presente. Nesse sentido, vale enfatizar as contribuições da Educação, Psicologia, Medicina e outras áreas, notadamente a partir do final do século XIX e durante o século XX, que lançaram luzes acerca da especificidade do desenvolvimento e aprendizagem da criança pequena. Contudo, o reconhecimento da importância do período de zero a seis anos para a constituição humana, alardeada pelas publicações acadêmicas e disponíveis a um número cada vez maior de leitores, não se traduziu em medidas eficientes e eficazes, promotoras de uma melhor qualidade de vida para a criança em desenvolvimento.

Dessa forma, a infância, na contemporaneidade, é marcada por um interessante paradoxo, tendo, de um lado, o reconhecimento da especificidade desse período de vida, em que uma série de estruturas mentais está em franco desenvolvimento, e, de outro, a observação de fenômenos como o trabalho infantil e o contínuo encurtamento do tempo dedicado às brincadeiras e outras linguagens próprias da infância em prol da preparação para um incerto mercado de trabalho. Rocha (2002) acrescenta que a inserção social da criança e a maior atenção dada à infância não implica no direito à infância, pois, para muitos, ainda se trata de um período preparatório para a fase adulta.

É interessante observar que as agendas das crianças estão cada vez mais similares às dos adultos. Há vários compromissos a serem cumpridos, como aulas variadas, ao longo do dia, o que denota a opção por dar importância a essa etapa da vida enquanto preparatória para o mundo adulto. Bignotto (2005) pondera que os pais, pensando no bom desempenho profissional futuro de seus filhos, acabam por desenvolver grandes expectativas nas atividades desempenhadas pelas crianças e o que deveria ser uma atividade esportiva e/ou recreativa, como, por exemplo, um jogo de futebol, acaba sendo visto como competição, sendo a vitória o resultado esperado.

Lipp (2000) considera que não só adultos, mas as crianças também sofrem por apresentar uma ambição exacerbada, capaz de causar desequilíbrio emocional e baixa autoestima, devido à avalanche de atividades a que estão sujeitas e que acabam por serem fontes geradoras de estresse. Horta (2007, p. 123) enfatiza a pertinência de se dispor de "informações que possam ser úteis ao diagnóstico, à compreensão e ao manejo do estresse em crianças pré-escolares, em decorrência das poucas possibilidades e capacidades para lidar com o grande número de fontes de estresse às quais estão expostas".

\section{Apontamentos sobre o Estresse Infantil}

Atualmente, é muito comum ouvir-se a palavra estresse utilizada em diferentes contextos e situações, comprometendo o próprio entendimento do conceito. Fontana (1994) argumenta que definir a palavra estresse não é fácil, por ser um termo usado por diferentes profissionais com significados diversos. Os médicos referem-se aos aspectos fisiológicos, os engenheiros, à resistência e os psicólogos, às mudanças de comportamento.

Hans Selye, então estudante de Medicina, ao buscar entender o mecanismo do adoecimento, foi quem, primeiramente, fez referência à palavra estresse ao pesquisar as reações não específicas ou não esperadas do organismo (Lipp \& Novaes, 2003). Para tanto, empregou o termo estresse, que é utilizado na engenharia para quantificar o peso que um objeto pode suportar até se alterar.

Contudo, Simmons (2000) alerta que o estresse não é gerado apenas por fatores considerados "negativos", como as doenças e acidentes, as perdas significativas e as mudanças abruptas, pois, no seu entender, o estresse pode ser originado por situações excitantes, que levam o organismo a um estado de exaustão devido ao grande número de eventos orgânicos e emocionais, inerentes ao episódio, causando esgotamento físico e mental devido à necessidade de adaptação do organismo. Portanto, o estresse pode ser definido como uma reação de adaptação a qualquer demanda e requer reajuste para restabelecer o equilíbrio.

Segundo Lipp, "o estresse é uma reação do organismo diante de situações ou muito difíceis ou muito excitantes, que podem ocorrer em qualquer pessoa, independentemente de idade, raça, sexo e situação socioeconômica." (Lipp, 2000 , p. 16). Para a autora, as possibilidades de enfrentamento de quadros com estressores dependem de variáveis da própria pessoa, como o estágio de vida em que se encontra e as características de sua personalidade.

Selye dividiu a síndrome do estresse em três fases, sendo a primeira denominada de fase de alerta, a qual inclui 
sensações como sudorese excessiva, taquicardia, respiração ofegante, entre outras; na segunda, há a resistência, em que o organismo realiza tentativas de recuperação do equilíbrio, havendo grande gasto de energia com sinais de cansaço excessivo, esquecimentos etc; e, na terceira, temse a exaustão, que se caracteriza com o agravamento dos sintomas físicos, assumindo a forma de doenças (Lipp \& Novaes, 2003).

Vieira (2002) enfatiza que a permanência do fator agressivo, na fase de exaustão, torna o organismo suscetível a várias enfermidades, como irritabilidade excessiva, depressão, baixa autoestima e aumento do colesterol, predispondo-o a doenças mais graves (gastrite, úlceras, infarto, hipertensão, câncer, acidente vascular cerebral, asma brônquica, depressão e doenças autoimunes). Lipp (2000) sugeriu a existência de uma fase intermediária entre a fase de resistência e exaustão que se caracteriza pelo estado de quase-exaustão, em que o indivíduo não encontra mais forças para superar os agentes estressores, apresentando comportamentos como falta de interesse, apatia, cansaço extremo e maior propensão ao desenvolvimento de doenças.

McEwen (2003) comparou as situações estressantes às que vivia o homem primitivo, como uma preparação do organismo a uma ameaça real, que o levava a lutar ou fugir. Todavia, acrescenta que, hoje, os estímulos deflagradores dessa reação são situações que fugir ou lutar não são opções, pois a mobilização da energia corporal em função do mecanismo do estresse não resulta na solução do problema.

A despeito da abrangente literatura da temática acerca do estresse em humanos, apenas em um passado recente foi possível detectar o aparecimento de estresse em crianças a partir dos seis anos de idade em contexto brasileiro, por meio dos estudos de Lipp (2000). A autora refere-se ao fato de que o estresse infantil é pouquíssimo conhecido, sendo difícil encontrar pesquisas, tanto no Brasil como em outros países. Por outro lado, Franca e Leal (2003) alertam que o problema do estresse na criança pequena é tão abrangente que chega a mobilizar oito em cada dez consultas pediátricas segundo o Instituto Americano de Stress, situado em Nova York.

Atrelado ao fato acima mencionado, têm-se que as crianças estão continuamente expostas a uma estimulação excessiva, propiciada pelo tecnicismo atual, a qual não é devidamente mediada, resultando em apatia da psique, conforme denuncia o psicólogo italiano Galimberti (2007). Slee, Murray-Harvey \& Ward (1996) identificaram eventos estressantes em um estudo com crianças de cinco anos de idade na seguinte ordem: hospitalização dos pais; separação dos pais; exigências disciplinares; hospitalização da criança; sequestro de membro da família; mudança de residência; ausência dos pais; morte de familiar; presenciar dificuldades de relacionamento dos pais; nascimento de irmão e mudança de emprego dos pais.

Para Lipp e Lucarelli (1998), as causas de estresse nas crianças a partir dos seis anos de idade estão relacionadas à morte na família; brigas constantes e separações dos pais; mudança de cidade ou escola; escolas ruins; profes- sores inadequados; atividades em excesso; viagens longas; espera de um acontecimento importante, dentre outras.

Bignoto (2005) chama a atenção para a relação estresse infantil e estresse no adulto. Tem-se que a presença de pessoas estressadas em torno da criança deve ser considerada, pois um indivíduo estressado pode apresentar irritação, hipersensibilidade, falta de paciência, intolerância e mal-estar físico, fatores que podem interferir na qualidade de suas interações com a criança.

Tavares (2004, p. 25) aponta que "pertencer e participar de um mundo externo além do nosso mundo interno implica conviver constantemente com uma dose de estresse. O estresse sob medida é um elemento vinculado ao processo de desenvolvimento". Assim, o estresse funciona tanto como uma força que pode facilitar como prejudicar o desenvolvimento, em que a energia vital dos impulsos deverá encontrar um caminho a despeito do estresse.

McFarlane e cols. (2005) evidenciaram, por meio de exames da atividade elétrica cerebral, a possível relação entre o estresse na infância com adversidades na vida adulta. Todavia, na prática, essas avaliações são difíceis de serem executadas, devido à falta de profissionais, equipamentos e, em se tratando de crianças, à dificuldade de aceitação das mesmas para tais procedimentos. Há, ainda, outros fatores que dificultam o diagnóstico de quadros de estresse em crianças, principalmente pela dificuldade das mesmas em descrever seus sentimentos e, além disso, pelo fato do estresse poder ser confundido com outras patologias (Lipp, 2003).

Considerando os instrumentos para a avaliação do estresse voltados para a população brasileira, tem-se a "Escala de Stress Infantil" - ESI, de Lipp e Lucarelli (1998), e a "Escala de Stress do Adulto"- ESA, de Lipp e Novaes (2003). Santos e Pacanaro (2007) ressaltam que a Escala de Stress Infantil (ESI) constitui-se no principal instrumento usado por pesquisadores para avaliação do estresse infantil a partir dos seis anos. Entretanto, há necessidade de se empreenderem novos estudos para a avaliação de crianças mais jovens, pois Horta (2007) já identificou indicadores de estresse em crianças pré-escolares.

Assim, os objetivos do presente estudo foram testar a viabilidade de uso de um instrumento elaborado para identificar estressores em crianças e descrever o estresse em crianças e como suas mães consideram o estresse na vida de seus filhos.

\section{Método}

\section{Participantes}

O trabalho foi realizado em uma creche que atende a uma população de filhos de trabalhadores rurais (safristas), situada na periferia de uma cidade do interior do Estado de Minas Gerais. Contou com a participação de 16 crianças, sendo oito de cinco anos e oito de quatro anos. Em relação 
ao gênero, havia 8 meninos e 8 meninas e 12 mães, sendo que alguns grupos foram formados por irmãos. $O$ projeto foi aprovado pelo Comitê de Ética para Pesquisa da Universidade Federal de Uberlândia (protocolo 043/09).

\section{A) Crianças}

De acordo com Oliveira-Formosinho (2008), pesquisas envolvendo crianças, nas quais as mesmas se constituem em fontes de dados devem ser realizadas por meio de atividades organizadas em grupos com cerca de três crianças. A Tabela 1 mostra como os grupos foram estruturados e também indica que a média de idade foi de 4,3 anos nos grupos 1, 2 e 3 e 5,4 anos nos grupos 4, 5 e 6 .

Tabela 1. Distribuição das crianças segundo a média de idade dos grupos.

\begin{tabular}{|c|c|c|}
\hline Grupo & Crianças $^{1}$ & Média de Idade \\
\hline $\mathbf{1}$ & Vander, Sara e Elias & 4,5 \\
\hline $\mathbf{2}$ & Ysrael, Marcos e Weber & 4,3 \\
\hline $\mathbf{3}$ & Walter, Janete & 4,3 \\
\hline $\mathbf{4}$ & Rita, Leda e Daniela & 5,4 \\
\hline $\mathbf{5}$ & Wilson e Tatiana & 5,5 \\
\hline $\mathbf{6}$ & Gabi, Jussara e Kin & 5,4 \\
\hline Total & & 4,9 \\
\hline
\end{tabular}

\section{B) Mães}

Participaram do estudo 12 mães, com idades que variaram entre 21 a 39 anos, sendo a maior concentração entre os 25 e 29 anos. No que respeita ao grau de escolaridade das mães, foi constatado que 10 possuem o Ensino Fundamental incompleto, 1 é analfabeta e 1 possui o Ensino Médio incompleto. Em relação à profissão das mães, a maior parte $(41,6 \%)$ tem emprego temporário, são "safristas" (trabalham apenas em épocas de colheita) e 33\% não trabalham fora; apenas uma das mães tem emprego fixo a maior parte do ano.

\section{Material}

Com a finalidade de conhecer possíveis indicadores de estresse em crianças pré-escolares, foram aplicados alguns materiais como:

1 Trata-se de nomes fictícios para preservar a identificação dos participantes.
2.1. Observação da rotina institucional.

2.2. Escala de fontes estressoras na criança (Lipp, 2005).

Esclarece-se que tal escala é composta por 40 itens, sendo atribuído a cada um deles uma pontuação específica. Ao final, somam-se os pontos e a pontuação obtida referese à probabilidade de ocorrência de problemas de saúde. A autora menciona que

Um total de pontos até 150 indica que a carga de stress atingiu nível médio. Uma somatória dos pontos de 150 a 300 indica que a criança tem uma probabilidade acima da média de ter alguns sintomas de mal-estar. Por sua vez, uma pontuação total acima de 300 significa que existe uma forte probabilidade de que a criança venha a apresentar problemas de saúde ou de comportamento, em virtude do stress excessivo a que ela está sujeita no momento (Lipp, 2005, p. 47).

2.3. Entrevista semiestruturada com as mães, contendo dados oriundos da literatura sobre o estresse, além de dados sociodemográficos, como:

* dados pessoais: idade, cidade de origem, estado civil, formação escolar e profissional.

* formas de interação com a criança.

* fatores da vida diária e da possível relação com o estresse infantil.

2.4. Kit "Deu estresse na bicharada", contendo uma história capaz de evocar narrativas infantis sobre situações de estresse e um tapete de pelúcia com personagens relativos à referida história, os quais propiciaram a mediação da pesquisadora, de acordo com os critérios mediacionais presentes no Programa MISC (Klein, 1996; Vectore, 2003, 2008). Vale frisar que a mediação é feita no sentido de clarificar para a criança o que é estresse, contribuindo para que possa identificá-lo em sua rotina.

Acerca do instrumento acima aludido, vale apontar que a elaboração da história foi feita a partir de alguns símbolos referentes à cultura ocidental, como, por exemplo, a cruz para simbolizar a morte. A história inicia-se com a tradicional frase: "Era uma vez" na tentativa de evocar os momentos já vividos diante de outras histórias já ouvidas. Segue apresentando seus personagens, entre eles uma família composta por pai, mãe e filhos, um menino de quatro anos e a sua irmã mais jovem.

A ambientação dá-se em uma floresta, onde os animais se encontram estressados. A criação dos personagens foi embasada em alguns princípios contidos no Teste de Apercepção Temática (CAT-A) e nos indicadores de estresse apontados na literatura e já anteriormente mencionados. Bellak (1992) salienta que o uso de animais é especialmente adequado para crianças a partir dos três anos de idade. Para Dieckman (1986), o uso das palavras "era uma vez" remete o ouvinte de volta a um tempo passado fora do pensamento racional onde acontecem coisas extraordinárias, entre elas a existência de seres mágicos e animais falantes. 
Acompanhando a história, o material inclui um tapete de pelúcia, que permite, ao ser colocado no chão, que as crianças sentem-se ao seu redor, tendo a pesquisadora/ mediadora no centro a fim de garantir as mediações junto às crianças. Além do tapete propriamente dito, há vários bonecos no formato de animais passíveis de serem manipulados pelas crianças e relacionados à temática.

2.5 Filmadora e gravador.

2.6. Identificação dos critérios mediacionais utilizados pela pesquisadora/mediadora durante as atividades com as crianças, conforme definidos abaixo:

* Focalização: inclui todas as tentativas do mediador para assegurar que a criança focalize a atenção em algo que está ao redor dela. Devem estar claras a indicação da intencionalidade do adulto para mediar e a reciprocidade da criança, a qual é expressa pelas suas respostas verbais e não verbais ao comportamento do adulto.

* Expansão: está presente quando o "educador" tenta ampliar a compreensão da criança daquilo que está à sua frente através da explicação, da comparação, adicionando novas experiências além das necessárias para o momento.

* Afetividade ou mediação do significado: refere-se a toda energia emocional utilizada pelo adulto durante a interação com a criança, levando-a a compreender o significado dos objetos, pessoas, relações e eventos ambientais.

* Recompensa: observada quando os adultos expressam satisfação com o comportamento das crianças e explicam o porquê de estarem satisfeitos, facilitando a elas sentimentos de autocontrole, de capacidade e sucesso, além de ampliar a sua disponibilidade para explorar ativamente o novo.

* Regulação do comportamento: é identificada quando o adulto ajuda a criança a planejar antes de agir, levando-a a se conscientizar da adequação do "pensar" antes de ação de modo que possa planejar os passos do seu comportamento para atingir um objetivo. Atender aos cinco critérios citados implica em atingir uma mediação adequada (Vectore, 2003).

\section{Procedimento}

A coleta de dados foi realizada por meio das entrevistas com as mães e por meio de oficinas efetivadas junto às crianças. As mães foram entrevistadas individualmente e responderam à Escala de fontes estressoras na criança (Lipp, 2005). Em seguida, os grupos foram formados de modo a se ter três grupos de crianças com quatro anos e três grupos com crianças com cinco anos de idade.

A primeira oficina teve o objetivo de familiarizar as crianças com os materiais audiovisuais (filmadora e gravador), com a pesquisadora e com a auxiliar de pesquisa que manuseava a filmadora. Vale mencionar que, para o registro das falas ocorridas no decorrer das oficinas, o gravador era colocado ao centro do tapete junto à pesquisadora e a filmadora era posicionada atrás da mesma, sendo manuseada pela auxiliar de pesquisa. Nessa sessão, esclareceu-se o objetivo do trabalho e foi solicitada às crianças a elaboração de um desenho livre, como forma de estabelecimento de um adequado rapport.

Nas três sessões seguintes, a pesquisadora preparou o local do encontro, dispondo o material, que consistiu em um tapete colocado no chão juntamente com a bolsa de camurça de cor azul contendo os personagens da história a ser contada. Quando as crianças chegavam, eram convidadas a se sentarem ao redor do tapete, tendo a pesquisadora ao centro. O procedimento das oficinas envolveu o acordo prévio junto às crianças: primeiramente, a pesquisadora contaria a história, após, elas contariam individualmente e, a seguir, poderiam brincar com os personagens ou desenhar.

Durante a narração da história, os personagens eram retirados um a um da bolsa azul e eram dispostos ao longo do tapete, formando o cenário. À medida que a narrativa prosseguia, o tapete era movimentado para dar lugar aos outros personagens. Ao final, ao longo do tapete, já se encontravam dispostos todos os personagens para que as crianças escolhessem por qual iriam iniciar a sua própria narrativa.

\section{Resultados}

Os resultados deste estudo são apresentados em três blocos, assim constituídos:

1. Dados oriundos das entrevistas com as mães.

2. Dados oriundos das observações na instituição.

3. Dados oriundos das oficinas com as crianças. Em relação a este tópico, vale mencionar que as oficinas foram analisadas visando localizar alguns episódios ou falas das crianças que retratam indicadores de estresse e, também, identificar o comportamento mediacional da pesquisadora, descrito no Programa MISC (focalização; expansão; mediação do significado; mediação dos sentimentos de recompensa e autorregulação), de modo a permitir a avaliação da mediação como forma facilitadora de expressão e entendimento da criança acerca do estresse em si e nos outros.

\section{Dados oriundos das entrevistas com as mães}

A primeira constatação importante desta pesquisa é que a maioria das crianças é oriunda de lares cujos pais têm pouca escolaridade e atividade profissional instável (safristas) ou estão desempregados, o que já pode ser um fator propiciador de estresse na família, haja vista que provavelmente sofram privações de ordem material, conforme o excerto abaixo: conforme pode ser depreendido no excerto

Mãe de Wilson: "Minha casa, eu construí pedindo material aqui e ali na cidade. Não posso sair de casa, não tem porta pra fechar. Hoje não tenho botijão pra cozinhar, os meninos chegam da escola e não tem comida pronta..." 
Tabela 2. Fontes de estresse apresentadas pelas mães

\begin{tabular}{|c|c|c|c|c|c|c|c|c|c|c|c|c|}
\hline Mães & $\mathbf{1}$ & $\mathbf{2}$ & $\mathbf{3}$ & $\mathbf{4}$ & $\mathbf{5}$ & $\mathbf{6}$ & $\mathbf{7}$ & $\mathbf{8}$ & $\mathbf{9}$ & $\mathbf{1 0}$ & $\mathbf{1 1}$ & $\mathbf{1 2}$ \\
\hline Dificuldade com os filhos & $\mathrm{X}$ & $\mathrm{x}$ & $\mathrm{x}$ & $\mathrm{x}$ & & & & $\mathrm{x}$ & & $\mathrm{x}$ & $\mathrm{x}$ & $\mathrm{x}$ \\
\hline Dificuldade financeira & & $\mathrm{x}$ & & $\mathrm{x}$ & $\mathrm{x}$ & $\mathrm{x}$ & & & $\mathrm{x}$ & & & \\
\hline Pressão no trabalho & & & & & & & & & & & & $\mathrm{x}$ \\
\hline Problemas de saúde & & & & & & & & & $\mathrm{x}$ & & $\mathrm{x}$ & \\
\hline Não se sente estressada & & & & & & & $\mathrm{x}$ & & & & & \\
\hline Mães & 1 & 2 & 3 & 4 & 5 & 6 & 7 & 8 & 9 & 10 & 11 & 12 \\
\hline Dificuldade com os filhos & $\mathrm{X}$ & $\mathrm{x}$ & $\mathrm{x}$ & $\mathrm{x}$ & & & & $\mathrm{x}$ & & $\mathrm{x}$ & $\mathrm{x}$ & $\mathrm{x}$ \\
\hline Dificuldade financeira & & $\mathrm{x}$ & & $\mathrm{x}$ & $\mathrm{x}$ & $\mathrm{x}$ & & & $\mathrm{x}$ & & & \\
\hline Pressão no trabalho & & & & & & & & & & & & $\mathrm{x}$ \\
\hline Problemas de saúde & & & & & & & & & $\mathrm{x}$ & & $\mathrm{x}$ & \\
\hline Não se sente estressada & & & & & & & $\mathrm{x}$ & & & & & \\
\hline
\end{tabular}

Em relação às fontes de estresse elencadas pelas mães, observa-se, pela Tabela 2, que dificuldades com os filhos são apontadas por $50 \%$ das mães entrevistadas, seguida de dificuldades financeiras $(33,3 \%)$, e apenas uma mãe não se sente estressada.

Em relação aos indicadores de estresse colhidos junto às mães a partir da Escala de fontes estressoras na criança (op.cit.), observa-se que as crianças participantes, em quase a sua totalidade, alcançaram uma pontuação indicativa de estresse severo, o que está relacionado, segundo o instrumento, com a probabilidade de ocorrência de problemas de saúde, conforme dados expressos da Tabela 3. Em especial, chama atenção a alta pontuação da criança 3 , indicativa de maior possibilidade de adoecimento.

Vale apontar que as mães consideram como fontes de estresse para seus filhos, principalmente, as constantes brigas com os irmãos e as dificuldades financeiras da família.

\section{Dados oriundos das observações na instituição}

Trata-se de uma instituição filantrópica mantida por doações de associações e de entidades religiosas do município e pelo Fundo de Manutenção e Desenvolvimento da Educação Básica e de Valorização dos profissionais da Educação - FUNDEBE. Atende cerca de sessenta e três crianças na faixa etária de zero a cinco anos. Com o intuito de conhecer a rotina da instituição, considerando que as crianças lá permanecem durante todo o dia, foram realizadas observações durante uma semana, com um total de 20 horas. O dia a dia é marcado por atividades como banho, refeições, lanches, brincadeiras ao ar livre, atividades no parquinho e desenhos no asfalto em frente à creche. Entre os temas de conversas, podem ser destacados episódios de embriagamento dos genitores e a presença de drogas na região (maconha).
Além disso, é importante mencionar que a instituição parece não dispor de atividades contínuas para as crianças, pois há vários momentos em que elas ficam ociosas, o que gera situações de conflitos, agitações etc, os quais se constituem em fontes estressoras, conforme salienta Lipp (2005).

\section{Dados oriundos das oficinas com as crianças}

Conforme anteriormente assinalado, as oficinas foram analisadas visando localizar alguns episódios ou falas das crianças que retratam indicadores de estresse e, também, identificar as possibilidades de mediação através do comportamento mediacional da pesquisadora segundo os critérios MISC, já apresentados.

A oficina 1 teve como objetivo familiarizar as crianças com a pesquisadora e com os instrumentos de coleta de dados, além de investigar a presença de indicadores mencionados anteriormente pelas mães, como, por exemplo, o medo. Para tanto, foram utilizados papéis de tamanho $\mathrm{A} 3 \mathrm{e}$ A4 para desenho das crianças, gravador e filmadora.

A narrativa abaixo demonstra o medo de Sara em ficar sozinha:

Sara: Tô escreveno um menininho, menininho pitinho! Ele entra dentro da casinha dele, ele vai ficar trancadinho.

Pesquisadora: Ele vai ficar trancado? Por quê?

Sara: Porque a mãe dele tranca ele (...) Ela foi na cidade e deixou ele aqui sozinho.

Foi possível também identificar, junto às crianças de cinco anos, o contato dessas com a violência no seu dia a dia, fator relacionado aos indicadores de estresse (Lipp, 2005) e confirmados nas entrevistas com as mães. 
Tabela 3. Grau de probabilidade de ocorrência de problemas de saúde nas crianças participantes

\begin{tabular}{|l|c|c|}
\hline Criança & Somatório & Probabilidade de ocorrência de problemas de saúde \\
\hline & 274 & Média \\
\hline & 458 & Severa \\
\hline & 615 & Severa \\
\hline & 510 & Severa \\
\hline & 559 & Severa \\
\hline & 450 & Severa \\
\hline & 440 & Severa \\
\hline & 487 & Severa \\
\hline & 493 & Severa \\
\hline & 371 & Severa \\
\hline & 329 & Severa \\
\hline & 514 & Severa \\
\hline & 392 & Severa \\
\hline & 577 & Severa \\
\hline & 440 & Severa \\
\hline & 455 & Severa \\
\hline & &
\end{tabular}

Tatiana: Mataram o tio da menina que mora perto da minha casa, só que ele é grande, ele matou o Gordo! (Nesta época, havia ocorrido um assassinato no bairro onde fica a instituição).

A oficina 2 objetivou familiarizar as crianças acerca do conceito de estresse por meio da aprendizagem mediada (Misc, 1996). Nessa atividade, foi utilizado o Kit "Deu estresse na bicharada!", papéis de tamanho A4, lápis de cor, gravador e filmadora. De modo geral, as crianças com quatro anos demonstraram mais interesse pelos animais e pelos objetos presentes no instrumento do que propriamente pela narrativa em si. Por outro lado, as crianças maiores mencionaram alguns indicadores de estresse, como, por exemplo, o ciúme devido ao nascimento do irmão.

$\mathrm{Na}$ oficina 3, buscou-se avaliar o conhecimento das crianças acerca do conceito de estresse trabalhado nas sessões anteriores por meio da utilização do referido kit.

As crianças dos grupos de cinco anos demonstraram maior capacidade para realizar comentários. Nesses grupos, apareceram temáticas relativas ao medo excessivo e medo da morte de um dos pais, o que está relacionado ao sentimento de desamparo pela perda de alguém muito querido (Lipp 2005, p. 29), exemplificado na fala de Rita:

Rita: Ela tava com medo de comer, ela tava com medo de sair sozinha, com medo de dormir, ela tava com medo de ficar sozinha, ela tava com medo de fazer alguma coisa. (Rita comenta a situação da girafa)

\section{Critérios mediacionais possibilitados pelo instrumento}

No presente estudo, a mediação da pesquisadora deu-se por meio da narrativa atrelada aos comportamentos mediacionais contidos no Programa MISC. Assim, a focalização refere-se a todas as tentativas de centrar a atenção da criança em um objeto ou situação, mostrando, por exemplo, o calendário para indicar a data do aniversário do personagem. A expansão ocorreu quando foi possível acrescentar dados à experiência imediata, incentivando relatos referentes ao tema, como:

Leda: O bebê é pequenininho! $E$ o pequenininho é pequenininho e ela é mais velha. Sabe fazer tudo sozinha. E os pais não gostam dela! ( $L$ fala da situação vivida pela oncinha ao ter um irmãozinho em casa, comparando o que cada um é capaz de fazer).

Mediação do significado: Dar significados ou sentidos, normalmente culturais, às situações vividas. 
Tatiana: Todo estressado será por quê? Porque a mamãe morreu. Aí a foquinha filhinha falou: Nossa! Coitadinha da mamãe! Aí, o macaco falou assim: Nossa! Eu tô estressado, porque tem muita coisa pra fazer, eu tenho que escrever, eu tenho que fazer muitas coisas. Eu tenho que coisar e jogar futebol.

Recompensa: Elogiar os comentários das crianças. Dar atenção e se interessar pela criança, dirigindo-lhe o olhar e, continuamente, mostrando-lhe a adequação de sua participação, entre outros.

Pesquisadora: (...) Foram visitar a oncinha! Isso mesmo Wilson! É isso mesmo!

Auto-regulação: Direcionar o comportamento da criança, explicando as consequências de seu comportamento, para que ela própria se autorregule.

Pesquisadora: Primeiro, eu vou contar a história, depois cada um de vocês vai poder contar a história para mim e pegar os animais.

A Tabela 4 sintetiza os critérios mediacionais utilizados pela pesquisadora no intuito de que as crianças compreendessem do que se trata o estresse. Pode-se observar que a maior frequência ocorreu no uso da focalização e a menor referiu-se à expansão.

Tabela 4. Critérios mediacionais utilizados pela pesquisadora junto às crianças

\begin{tabular}{|l|c|}
\hline Critério & Frequência \\
\hline Focalização & 238 \\
Expansão & 58 \\
Mediação do Significado/Afetividade & 194 \\
Recompensa & 207 \\
Autorregulação & 126 \\
\hline
\end{tabular}

\section{Discussão}

Compreender e explicar a possível presença de indicadores de estresse no dia a dia de crianças pré-escolares por meio de recursos que possibilitam a mediação do adulto junto aos pequenos foi o objetivo perseguido por este empenho de pesquisa que, apesar de suas modestíssimas proporções e intenções, parece lançar alguma luz em relação aos aspectos em jogo na identificação do estresse infantil. A discussão dos resultados mencionados anteriormente, que ocupará este capítulo, apóia-se de modo predominante em contribuições científicas originadas da teorização e pesquisa acerca da aprendizagem mediada.

Um dado digno de atenção é o da própria constituição da amostra de mães. A maioria tem pouca escolaridade, atividade profissional instável (safristas) ou está desempregada, o que certamente determina um quadro contínuo de privação material a que estão submetidas. A relação estresse e dificuldades econômicas tem sido estudada em contexto brasileiro, conforme pesquisas de Fleck \& Wagner (2003), Lopes; Faerstein, \& Chor (2003) e Robaina e cols. (2009).

Além disso, as mães sentem muitas dificuldades em lidarem com os filhos. Tal dificuldade pode estar ligada à falta de tempo e ao acesso restrito a informações acerca do desenvolvimento infantil, entre outros aspectos que devem ser mais bem investigados. Contudo, das doze mães pesquisadas, apenas uma disse não se sentir estressada, o que representa menos de $10 \%$ das participantes.

Como mães de pouca escolaridade e pertencentes aos estratos desfavorecidos da sociedade entendem e costumam avaliar o estresse em seus filhos? Preliminarmente, chama a atenção o fato de que apontam uma série de fontes estressoras em suas crianças, como as brigas constantes com os irmãos, o trabalho fora de casa e a piora da situação financeira familiar, de modo que todos esses indicadores somados levam a uma alta possibilidade das crianças investigadas apresentarem problemas de saúde.

Contudo, dentre as crianças participantes, somente uma apresentou um grau mais elevado de estresse; as demais parecem apresentar comportamentos típicos de seu estágio de vida, como medos, ciúmes etc. Assim, uma questão que se coloca é a pertinência de tal escala para uma população como a aqui relatada, sugerindo a necessidade de novas investigações científicas.

Em relação aos dados oriundos das observações realizadas na instituição, pode-se dizer que a rotina das crianças envolve atividades de vida diária, como refeições, lanche e banho, mas também é pontuada por brincadeiras ao ar livre no parquinho e desenhos no afasto, entre outras tipicamente escolares ou conteudistas que ocorrem no período da tarde. Assim, observa-se que, a despeito da pobreza dos lares dessas crianças, a instituição propicia momentos de descontração e ludicidade, o que pode contribuir com diminuição do peso dos estressores presentes na realidade das mesmas.

Por outro lado, uma das mães insiste em dizer que as crianças não brincam, referindo-se ao caráter pedagógico de algumas brincadeiras. Nesse sentido, foi observado que as crianças permanecem ociosas em alguns períodos do dia, notadamente no momento em que esperam os pais buscálas, o que poderia talvez ser revisto na programação da creche, pois acaba por gerar conflitos e brigas entre elas.

Considerando as oficinas organizadas para as crianças, utilizando-se de narrativa, uma primeira indagação refere-se a sua pertinência junto aos pequenos. De acordo com os dados coletados, o grupo de crianças com cerca de quatro anos manifestou pouco envolvimento em relação à história propriamente dita, observado pelos momentos de 
dispersão, e apresentou maior interesse pela descrição do material do que pelo tema.

Assim, conhecer os animais, os enfeites e adereços que usavam e os objetos que faziam parte da história e do cenário constituíram o motivo de curiosidade e inúmeras perguntas das crianças dos grupos de quatro anos, exigindo da pesquisadora maior empenho nessa descrição apesar da tentativa de focar em outros pontos como, por exemplo, os acontecimentos que envolviam os animais em situações de estresse. A narrativa, quando não inexistente, limitou-se a um ou outro animal.

Desse modo, a apresentação da história simultaneamente à possibilidade de exploração dos personagens parece ter criado uma competição entre o estímulo auditivo e o tátil-cinestésico, muito mais saliente para crianças nessa faixa etária. Hall (2003), em um estudo experimental, mostrou que a mera exposição a um estímulo pode influenciar a sua eficácia perceptiva, o que sugere a importância de talvez trabalhar primeiramente com as possibilidades do tapete, para, na sequência, introduzir a narrativa.

Por outro lado, nos grupos de crianças com cerca de cinco anos, a forma como foram organizadas as oficinas parece ter despertado maior interesse e merece ser considerada como uma estratégia adequada para uso em estudos posteriores, haja vista que as crianças foram capazes de narrar os fatos acontecidos com os animais e demonstraram interesse em fazer tais narrativas.

Durante a realização da pesquisa, um dado que merece destaque refere-se à capacidade das crianças em realizar várias observações sobre a temática do estresse. Algumas crianças emitiram pareceres, ratificaram situações vividas pelos animais e acrescentaram seus conhecimentos do mundo, transcendendo as informações dadas, parecendo compreender o que é o estresse e como ele pode estar presente no dia a dia de suas vidas, como, por exemplo, quando nasce um irmãozinho e quando se tem medo de ficar só.

A despeito das dificuldades iniciais com as crianças menores, de um modo geral, tem-se que as mesmas demonstraram gostar dos materiais usados e de participarem das oficinas a ponto de não querer que se encerrassem. Mesmo quando a narrativa ocorreu pela segunda vez e o tapete, a história e os animais não eram mais novidade.

Além disso, o uso do tapete e dos animais estimulou o desejo de recontar as histórias. Houve crianças que passaram a contar suas próprias histórias, criando outros motivos, acrescentando novas ações dos personagens, isto é, transcendendo ou expandindo em relação ao critério mediacional. Vale apontar que, de acordo com os fundamentos do programa MISC, a criança que é efetivamente mediada torna-se também um mediador (Klein, 1996).

Considerando tal aspecto, vale mencionar as observações feitas pelas crianças ao instrumento utilizado, as quais poderão ser incorporadas a fim de torná-lo mais eficiente e adequado para o trabalho junto aos pequenos. Por exemplo, pode ser citado o comentário de uma das crianças que observou que a fisionomia do macaco estava alegre, embora ele vivesse estressado devido às múltiplas atividades que tinha que cumprir e, portando, não deveria esboçar um sorriso.

Outra contribuição das crianças ao instrumento refere-se à dificuldade de compreender a expressão facial exibida pela foca falecida, pois os seus olhos foram bordados em linha em forma de cruz, dando a impressão de terem sido arrancados. Como opção, pode-se colocar olhos que possam abrir e fechar. A cama do elefante também foi motivo de observações pelas crianças. A pesquisadora evitava colocá-la, pois a sua representação no material EVA ficou estranha ao ser representada. A melhor forma seria uma cama em três dimensões feita com material dobrável ou para montagem durante a narrativa.

A despeito da necessidade de ajuste do Kit elaborado para a presente pesquisa, foi possível observar que o mesmo propiciou às crianças a transcendência das situações vivenciadas, haja vista que falaram sobre acontecimentos que poderiam contribuir para deixá-los mais estressados, como, por exemplo, o nascimento de um irmão.

A pesquisa preocupou-se em saber quais são os critérios mediacionais que podem ser utilizados pelos mediadores para o trabalho junto às crianças de modo que possa otimizar o reconhecimento do estresse em si e nos outros, considerando que a pouca idade das mesmas exige uma série de estratégias para iniciar a avaliação da existência ou não de estresse. Assim, no presente estudo, a própria pesquisadora assumiu o papel de mediadora, tendo, para tanto, lançado uso dos seguintes critérios mediacionais, na presente ordem: focalização; recompensa; mediação do significado; autorregulação e expansão.

Focalizar significa tentar manter a atenção da criança focada ou direcionada para o que deve ser ensinado e, nesse critério, a criança deve emitir comportamentos verbais ou não relativos à intencionalidade do mediador. Assim, como a mediadora/pesquisadora queria ensinar o conceito de estresse para as crianças é esperado que seja utilizado tal critério em um número expressivo de situações. Além disso, por se tratar de crianças pequenas, outro critério importante para efetivar a mediação diz respeito à recompensa, no qual a mediação dá-se por um feedback rápido e esclarecedor acerca da adequação de seus comportamentos. Em relação à mediação do significado ou afetividade, pode-se pensar na importância que assume neste trabalho, em que continuamente foi necessário dar significado acerca dos sentimentos que envolvem o estresse, como, por exemplo, o medo manifestado pelas crianças. A autorregulação também esteve presente, haja vista sua necessidade para regular o comportamento das crianças e fazerem com que planejem antes de agir. Em relação ao critério expansão, neste estudo, esteve em menor frequência, possivelmente por se trabalhar com crianças pequenas, entre as quais a manutenção da atenção é uma condição imprescindível para qualquer ensinamento, havendo uma maior necessidade de se focalizar do que propriamente de transcender as informações aprendidas. 


\section{Considerações finais}

O instrumento elaborado para este estudo intitulado "Deu estresse na bicharada!" pode facilitar a compreensão e a comunicação da criança de situações cuja vivência subjetiva não raras vezes passa despercebida pelos familiares e pelas pessoas próximas. Assim, a identificação propiciada pelo instrumento com os colegas e com os personagens parece tornar favorável o alívio dos possíveis sintomas, como medo, rejeição e outros, pelo fato da criança poder expressar e compartilhar seus sentimentos.

Vale apontar a pertinência da aplicação do instrumento em pequenos grupos, pois facilita o confronto e a troca de diferentes pontos de vista, objetivando uma síntese do grupo. Neste estudo, foi possível observar que o uso do tapete de histórias constituiu-se em um instrumento adequado, principalmente para uso com crianças de cinco anos, pois, ao mesmo tempo em que avalia um sinal ou sintoma, propicia a expressão dos sentimentos infantis, tendo na ação avaliativa a possibilidade da intervenção. Contudo, são necessários novos estudos que possibilitem a compreensão acerca do estresse em crianças pequenas e também que se avalie a viabilidade do uso do material aqui descrito.

Outro dado que a pesquisa lança luz refere-se à consideração dos indicadores da literatura presentes na Escala de fontes estressoras para crianças (Lipp, 2000), considerando que, nas entrevistas com as mães, as crianças alcançaram pontuações indicativas de um período de quase exaustão e exaustão, o que não pôde ser confirmado por meio dos procedimentos utilizados durante as oficinas. De modo geral, as crianças mostraram-se ativas, dispostas e alegres. Daí tem-se a pertinência de se realizar investigações com as crianças, dando-lhes a voz e acreditando serem sujeitos competentes na sua expressão.

Neste estudo, as crianças parecem ser resilientes e também disporem de fatores de proteção. Entre eles, talvez a creche possa ser considerada como um fator protetor, pois as crianças ali permanecem cerca de oito horas diárias, são alimentadas e cuidadas, estando, de certa forma, durante esse período, livres das privações que a carência financeira impõe. Hutz, Koller e Bandeira (1996) consideram a instituição escolar, para crianças em situação de risco social ou pessoal, como promotora do desenvolvimento, pois há a possibilidade de se ter apoio e proteção contra a violência doméstica, entre outros fatores.

De tudo o que foi dito, pode-se concluir que a compreensão do estresse infantil deve ser continuamente investigada de modo a se dispor de instrumentos fidedignos, capazes de efetivamente avaliarem quadros de estresse na infância, considerando que, com as transformações inerentes à exigente sociedade globalizada, vários sintomas de estresse deverão estar presentes em maior número e de modo mais frequente junto às crianças. Assim, a devida avaliação e encaminhamentos adequados podem promover um desenvolvimento saudável em todos os aspectos e contribuir para a compreensão do intrincado quebra-cabeça que se constitui a construção de um ser humano.

\section{Referências}

Bellak, L. (1992). Teste de Apercepção Temática - CAT. São Paulo: Casa do Psicólogo.

Bignotto, M. M. (2005). O papel dos pais na prevenção do stress infantil. Em M. E. N. Lipp, Crianças estressadas: causas, sintomas e soluções (4a Ed). Campinas, SP: Papirus.

Dieckman, H. (1986). Contos de Fadas vividos. São Paulo: Paulinas.

Fontana, D. (2004). Estresse: Faça dele um aliado e exercite a autodefesa (2a ed.). São Paulo: Saraiva.

Franca, C. A., \& Leal, E. Q. (2003). A influência do stress excessivo no desenvolvimento da criança. In: M. E. N. Lipp, Mecanismos Neuropsicofisológicos do Stress: Teoria e Aplicações Clínicas. São Paulo: Casa do Psicólogo.

Fleck, A. C., \& Wagner, A. (2003). A mulher como a principal provedora do sustento econômico familiar. Psicologia em Estudo, 8(num. esp.), p. 31-38.

Galimberti, U. (2007). Os perigos da técnica. Revista Educação, 124. Disponível em: http://revistaeducacao.uol.com.br/textos. asp? codigo $=12233$

Hall, G. (2003). Learned changes in the sensitivity of stimulus representations: Associative and nonassociative mechanisms. The Quarterly Journal of Experimental Psychology, 56B (1), 43-55.

Horta, L. R. (2007). Estresse infantil: um estudo exploratório com pré-escolares. Dissertação de Mestrado, Universidade Federal de Uberlândia, Uberlândia, Minas Gerais.

Hutz, C., Koller, S. H., \& Bandeira, D. R. (1996). Resiliência e vulnerabilidade em crianças em situação de risco. Coletâneas da ANPEPP, 1(12), p. 79-86.

Klein, P. S. (1996). Early intervention: Cross-cultural experiences with a mendiational approach. New York: Garland Publishers.

Lipp, M. E. N. (2000). Manual do Inventário de Sintomas de Stress em Adultos. São Paulo: Casa do Psicólogo.

Lipp, M. E. N. (Org.). (2003). Mecanismos neuropsicofisiológicos do stress: teoria e aplicações clínicas. São Paulo: Casa do Psicólogo.

Lipp, M. E. N. (Org.). (2005). Crianças estressadas: causas, sintomas e soluções (4a ed.). Campinas, SP: Papirus.

Lipp, M. E. N., \& Lucarelli, M.D.N. (1998). Escala de Stress Infantil: ESI: manual. São Paulo: Casa do Psicólogo.

Lipp, M. N., \& Novaes, L. E. (2003). Conhecer e enfrentar o stress (5a ed.). São Paulo: Contexto. 
Lopes, C. S., Faerstein, E., \& Chor, D. (2003). Eventos de vida produtores de estresse e transtornos mentais comuns: resultados do Estudo Pró-Saúde. Cad. Saúde Pública, 19(6), p. 1713-1720.

McEwen, B. S. (2003). O fim do estresse como nós conhecemos. Rio de Janeiro: Nova Fronteira.

McFarlane A., Clark, C. R., Bryant, R. A., Williams, L. M., Niaura, R., Paul, R. H., Hitsman, B. L., Stroud, L., Alexander, D. M., \& Gordon E. (2005). The impact of early life stress on psychophysiological, personality and behavioral measures in 740 non-clinical subjects. J Integr Neurosci. 4(1), p. 27-40.

Oliveira-Formosinho, J. (Org.). (2008). A escola vista pelas crianças. Porto: Porto Editora.

Santos, A. A. A., \& Pacanaro, S. V. (2007). Avaliação do estresse no contexto educacional: análise de produção científica. Avaliação Psicológica, 6, 253-260.

Robaina, J. R, Lopes, C. S., Rotenberg, L., Faerstein, E., Fischer, F. M., Moreno, C. R. C., Werneck, G. L., \& Chor, D. (2009). Eventos de vida produtores de estresse e queixas de insônia entre auxiliares de enfermagem de um hospital universitário no Rio de Janeiro: estudo Pró-Saúde. Rev. bras. epidemiol.,12(3), 501-509.
Rocha, E. A. C. (2002). Criança e infâncias: uma categoria social em debate. Em III Congresso de Arte-Educação de Blumenau. Blumenau, SC, maio.

Simmons, R. (2000). Estresse: esclarecendo suas dúvidas. SP: Ágora.

Slee, P., Murray-Harvey, R. \& Ward, H. (1996). Stressed Out \& Growing Up. Every Child: School of Education, 2(4).

Tavares, M. C. G. C. (2004). Imagem corporal: conceito e desenvolvimento. São Paulo: Manole.

Vectore, C. (2003). O brincar e a intervenção mediacional na formação de professores da educação infantil. Psicologia USP 14(3), 105131.

Vectore, C. (2008). Desvendando o imaginário infantil. Relatório de Pesquisa, encaminhado e aprovado pela Fapemig.

Vieira, M. J. F. (2002) As funções orgânicas diante do estresse. Em M. A. A. Arantes (Org.), Estresse. São Paulo: Casa do Psicólogo.

\section{Sobre as autoras}

Célia Vectore (vectore@ufu.br)

Universidade Federal de Uberlândia, Uberlândia - MG

Luciana de Souza Zumstein (luciana@dhonline.com.br)

Universidade Federal de Uberlândia, Uberlândia - MG

\section{Correspondência}

Célia Vectore

Rua: Delmira Cândida Rodrigues da Cunha, 1279 - Uberlândia/MG - CEP: 38.408-208

\section{Agradecimento}

Apoio da FAPEMIG 